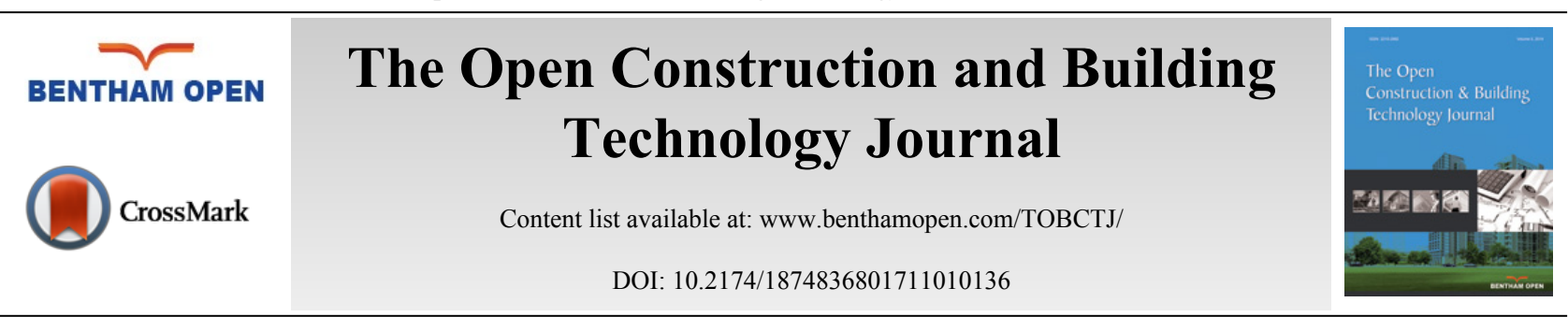

RESEARCH ARTICLE

\title{
The Information Requirements for Transportation Industry's Facilities Management Based on BIM
}

\author{
Qing Liu ${ }^{*}$ and Tao Gao \\ Construction Management, School of Mechanics and Civil Engineering, China University of Mining and Technology, \\ China
}

\begin{abstract}
In recent decades, Building Information Modeling (BIM) is well-known and has been widely accepted by AEC industry since it could make less mistakes, conflicts, and bring more profits as well as improve the level of communication and coordination. However, in the Operation and Maintenance phase, most of the owners including the transit agencies, still lack the knowledge about what BIM deliverables and processes to demand and how to facilitate and encourage other stakeholders to apply BIM technology. Therefore, this research aims to support Public transit authority in adopting and utilizing BIM processes by means of assessing their current BIM execution status. Through conducting a survey and interview in transit agencies owners, this research focuses on what kind of information requirements the facilities management for BIM deliverables is demanding and how these deliverables are being jointly used for facilities management after completing the handover process of the public transit industry.
\end{abstract}

Keywords: Facilities management, BIM, BIM deliverables, Information requirement, Handover process, Public Transit.

\section{INTRODUCTION}

Before the emergence of Building Information Modeling (BIM) technology, most of the facility managers used Autodesk CAD files to perform facility/asset management. However, there are several problems by using CAD files in facility management, such as the lack of correlative information integrated within the CAD drawings, inefficient coordination between different specialties and the complexity to interoperate other software [1].These problems can also be found during the process of infrastructure construction. Imperfect and uncompleted information exchange causes frequent loss of information and data need to be re-produced [2].

BIM can be defined as "a digital representation of physical and functional characteristics of a facility" [3]. Over the past decades, BIM had received much attention from both academia and the AEC/FM industry due to a large amount of benefits and resource savings during design, planning, and construction of buildings. Apart from being a powerful database, BIM technology also has the ability to change the way of project delivery to be a more integrated, efficient process. As a highly collaborative and data-rich environment, BIM is conducive to eliminating information loss and leveraging the data in BIM models to improve communication and collaboration between all the project stakeholders. It provides an opportunity to share building information during the initial design,construction, building operations, and renovation or retrofit of the project.

Every transit authority aims to augment the level of reliability, public safety, and achieve a better level of service [4] that should be considered under constraints of limited budget, implying any transit authority tends to maintain the level of service at an acceptable level. In this case, it is of great importance to decide which maintenance measures could give better level of service by taking the budget into consideration [5]. Till now, CAD drawings have still been used in a lot of asset management plans with little or no component attributes information integrated to identify different components and items. BIM is featured with better visualization of facility or asset and fully integrating information of com-

* Address correspondence to this author at the Construction Management, School of Mechanics and Civil Engineering, China University of Mining and Technology No.1 Daxue Street, Xuzhou, Jiangsu, China; Tel: (86)-17702585890; E-mail: liuqingcumt@126.com 
ponents, so the information and data could be shared among stakeholders better [1], which is challenging achieved by using CAD drawings.

Along with BIM technology being used by an increasing number of owners in their projects, the BIM processes and technology are also improved. However, the quality and level of BIM implementation vary among different organizations. Therefore, as the driving force of adopting BIM technology in project life cycle, it is critical for transit owners to have an adequate and mature BIM standard, BIM execution plan or BIM guideline. This research is aiming to analyze the level of BIM implementation among transit authorities and propose a framework of BIM information requirements to facilitate the facilities management process more efficiently and effectively.

\section{LITERATURE REVIEW}

Considering that BIM is a tool to manage accurate building information of the whole life cycle, it is suitable to support data for maintenance and deconstruction processes. Potential benefits of using BIM in O\&M are significant [2, 6] e.g. as valuable 'as-built' (heritage) documentation [7], maintenance of warranty and service information [5, 8], assessment and monitoring $[4,9]$, energy and space management $[4,10]$, emergency management or retrofit planning $[5,11]$. Despite the fact of that owners will be potentially benefited the most by using the facility model and its embedded knowledge of the facility's life cycle [12], the use of BIM in O\&M is still falling behind design and construction application. It is widely admitted that information requirements of most facility organizations are also quite diverse. Lewis (2012) proposed the abundance of data, as one of the challenges for the facility management in reaching the full potential of BIM. Moreover, considering there is no institutionalized "best practice" for owners to use BIM in the FM sector, it is very common for some owners just to adopt deliverable requirements in the existing contract with another organization, but owners should add their meaningful data needs to achieve the desired closeout requirements [13]. Hence, before the owners could propose their BIM deliverables, they should first have a good understanding of the taxonomy and standards for the information that they really need for.

\subsection{Data Exchange Standards}

To support new information workflows and adopt new digital information technologies, some standards of data exchange in the AEC/FM industry are undergoing development, e.g. NBIMs, IFC, COBie, OmniClass and UniFormat the framework of building information classification.

The National Building Model Standard (NBIMS), developed by the buildingSMART alliance (bSa), is an open standard to guide the use of BIM technology for building information exchanges. Meanwhile, the bSa suggests using IFCs (Industry Foundation Classes) as the data exchange standard, since the IFC format is a vendor-independent and open data format for information transferring and integration between digital building models and different kinds of information management systems.

The COBie project initiated in 2006 and funded by U.S. National Aeronautics and Space Administration (NASA), which aims to identify the information exchange needs of facility maintainers, operators, and asset managers of data available upstream in the facility lifecycle [14]. Although COBie may eventually provide a structure for the seamless transfer of data from BIM applications to FM data systems, nowadays, COBie relies on organizing data in a series of structured and related spreadsheets. It is unavoidable for it to determine how much information is optimal to be included directly in the model.

OmniClass has become an object-oriented standard for BIM data, particularly in terms of the data exchange methods such as the Construction Operations Building Information Exchange (COBie) [13]. UniFormat has emerged as a significant classification structure for specifying building information in a model [15].

\subsection{The BIM Application Requirements for Owners}

To improve the quality of information handover process and BIM deliverables for owners to use in the O\&M phase, most of the owners, including large building owners, government agencies and higher education institutions have begun to make specific requirements for BIM implementation, such as BIM guidelines, contractual language and standards.

\subsubsection{Government Agencies}

In 2003, with the purpose of improving design, construction and delivery quality, General Services Administration (GSA) established "National 3D-4D BIM program" to adopt BIM on all new projects undertaken in 2006 [16]. In 
addition, GSA proposed eight BIM Guide Series of specific requirements on BIM-based projects in the following years [17].

In 2006, the Army Corps of Engineers Engineer Research and Development Center (ERDC) published its own BIM roadmap outlining BIM implementation strategies for military construction and civil works projects [18].

In 2010, the department of Veterans Affairs published its VA BIM Guide. The guide includes the organization's life-cycle vision, implementation strategies, roles and responsibilities of different stakeholders, model sharing practices and requirements for using BIM as well as an in-depth set of standards for model applications and paper deliverables [19].

\subsubsection{Large Building Owners}

The BIM guides, standards and contracts proposed by large building owner organizations could be divided into two categories: one is adding the increased requirements for the use of a project-specific BIM execution plan as referenced in Docs 301 and another is the supplemental distribution of model element matrices aimed at establishing the level of detail requirement for each BIM object in the model [20]. The VA is one of many owners that requires the use of such documents.

\subsubsection{Higher Education Institutions}

In addition, a large number of higher education institutions also have been working on the development of BIM execution plans. In 2009, Indiana University published an organizational BIM Guidelines and Standards which also included three project-specific templates: an execution plan, an IPD methodology plan and a BIM proficiency matrix [21]. In October 2009, shortly after IU issued these documents, Pennsylvania State University published its own Project Execution Planning Guide. The guide outlines a four-step procedure for developing a detailed BIM execution plan, which can be customized by any project team wishing to implement BIM. Perhaps, the most useful content that it provided was the synthesis of the different categories of information suggested to be integrated into a BIM Execution Plan (BEP) [22]. Finally, Autodesk also put forward its Revit-centric version of a BEP that was termed as the "Project BIM Deployment Plan" developed in 2010. It closely resembled the BIM execution plan template developed by IU [20].

\subsection{Potential Benefits of BIM for Asset Management}

In the public transit industry, a great number of agencies operate various types of transportation, e.g. light rail, subway, commuter train, bus, streetcar etc. The facility managers and asset planning \& programming managers make too much effort to acquire the transition documentation needed to manage their assets (including Complete documented inventory, Equipment quantity and unit costs, Project Asset Assembly quantities and unit costs etc.) and especially when all of the information have been generated from the Design and Construction process already. They spent tens of thousands of dollars currently on a consultant to "regenerate" the lost data for several facilities, since with the right contract specifications for Asset Management, all of these data would be captured during the entire Design and Construction process timely. Meanwhile,the data is available many times in each stage of the process, thus, it should be captured and reviewed when it is available, instead of gathering and submitting the information in the antiquated and fragmented manner such as collecting all of it at the end of the project.

Using BIM for the facility management could creating the equipment inventory lists automatically in the way of populating the owner's CMMS or CAFM system, which is conducive to reduce the manual efforts and time when enter the documentation into another platform for facility use during the handover process [23]. Moreover, with the characteristic of automatic identification, BIM could also provide existing building condition information of higher precision than AutoCAD, which is extremely beneficial for space managers.

Besides, a huge amount of data, information and files, e.g. contracts, procurement files, warranty information, purchase requests, operation and maintenance manuals and inspection report etc., could be linked or integrated with the BIM model via URL and/or external or internal servers [24], which can save a lot of time and cost for facility managers. Take warranties as example, all warranty information can be retrieved easily and every maintenance action can be recorded with details associated with the maintained component through using BIM, which will supply maintenance workers with a good history record for each component. 
Apart from that, it is very beneficial for the asset manager to make a proper decision (e.g., replace, repair, preventive maintenance, or do-nothing) to deal with equipment and facilities in different conditions. As long as there is information about relevant components in BIM, relevant costs can be calculated. The costs of every action can be estimated with the BIM model and it has impact on the whole level of service of the subway station [1].

\section{RESEARCH METHODOLOGY}

Since using BIM in operations and maintenance phase in public transit industry is still new, there are few data on this topic. Thus, to gather data for this research, interviews and online survey methods are adopted.

\subsection{The Online Survey}

The online survey was designed to determine the respondents' experience, interest of BIM application in Facility management, to explore what areas BIM could bring value to the FM and what extent BIM currently utilized in FM field of Urban Railway Transportation industry at the process level. The online survey of 28 questions fell into four distinct parts: a section on demographics, a section on BIM adoption in FM, a section on BIM uses and required format of deliverables.

The survey was hosted on https://catalyst.uw.edu/webq/survey/qingliu/252653 through an account created by University of Washington's School of Build Environment. The survey link was directly distributed to facility owners and managers of transit agency of several transit authorities in different states of US and China, such as Sound Transit Agency (Seattle), Metropolitan Atlanta Rapid Transit Authority, Metropolitan Transportation Authority (New York), Los Angeles County Metropolitan Transportation Authority, San Francisco Municipal Transportation Agency, Chicago Transit Authority from Nov. 10, 2014 to DEC. 15, 2014 and Beijing, Nanjing, Shenzhen subway authorizes from Jan. 1, 2015 to Mar. 1, 2015.

\subsection{Interviews}

Before conducting the persona interviews, our research team investigated a typical process of FM organization that is in need of a digital information handover and management tool and is potentially suitable for BIM implementation, after that, the following personas including the link facilities maintenance manager, the facilities project manager, senior facilities coordinators, and senior facilities specialists were selected. Thus, the interviews were conducted to examine FM functions and processes, and how BIM could potentially improve personnel and process efficiency.

The personal interviews were conducted with the support of FM department of Sound Transit agency during March 2015. The face-to-face persona interviews include the following main areas aspects: interviewee's background, position information, work flow and data requirements, challenges of BIM for FM.

\section{RESULTS}

So far, the survey has received a total of 24 complete responses and 3 partial responses. Since it is impossible to determine the exact number of people who received the survey link considering that people who got it had the ability to forward it to anyone they thought suitable, and the response rate can only be calculated based on the number of visits and complete and partial responses. The response rate was $(24+3) / 112=24.11 \%$, while the effective response rate was $24 / 112=21.43 \%$.

\subsection{Status of BIM Implementation in Facilities Management}

According to the demographic information, the respondents play different roles in their organizations and most of them undertake multiple responsibilities within their organizations. The most common roles indicated by respondents include assistance with asset planning and control, condition assessment, facilities management and maintenance.

When being asked whether they adopted BIM to support any phase of project's life cycle (design, construction, operations and maintenance stage), $80 \%$ of the respondents answered that BIM was adopted in their new projects by their organizations. However, only one-fourth of these organizations were using BIM in the operation and maintenance phase. In this study, The BIM users and non-BIM users were analyzed separately.

As this study focused on utilizing BIM in operations and maintenance stages, the respondents were asked to choose the potential FM application areas that could be brought values by leveraging BIM (Fig. 1). 


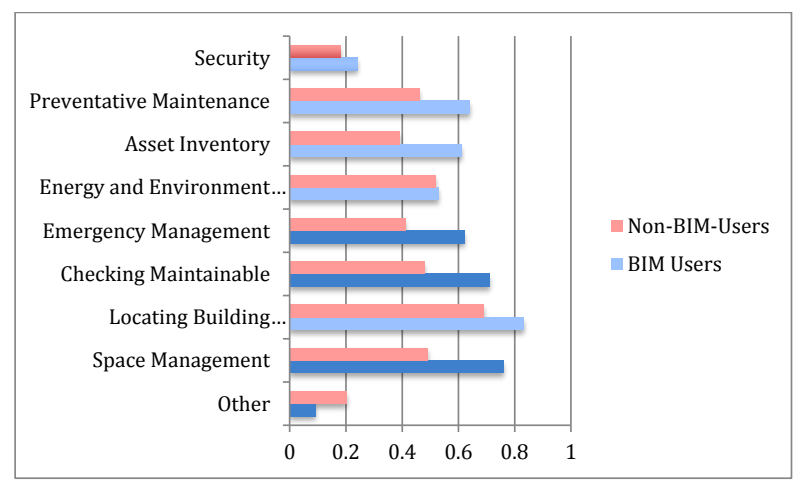

Fig. (1). Potential FM application areas that BIM can be used for.

When being asked about the convenience of the handover method for different purposes during the O\&M phase, the respondents who are not using BIM expressed overall lower satisfaction in the usability of the information handed over than those who are using BIM (Fig. 2).

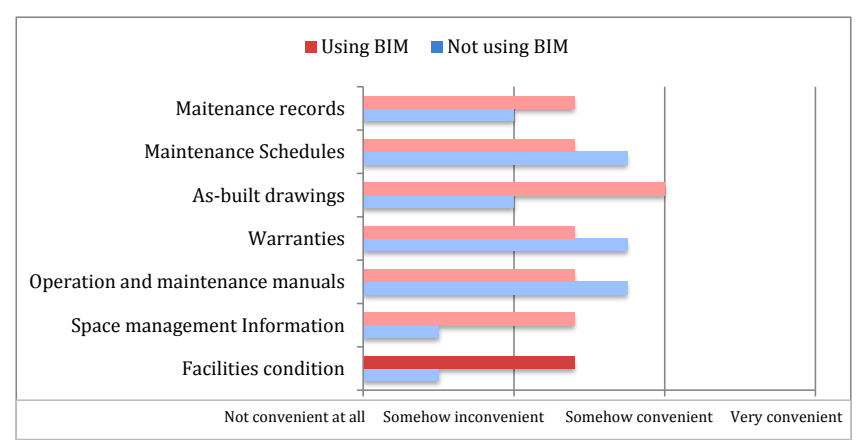

Fig. (2). Convenience of the information delivery methods for the use of different type of information at the operation and maintenance stage for transit agency.

\subsection{Data Requirements to Support Facilities Management Based on BIM}

When asked what information was needed for Asset Management, different respondents according to their working requirements chose the most important and high priority data and information according to their working requirements, which could be concluded as the following Table 1.

Table 1. Data requirements for facilities management.

\begin{tabular}{|c|c|c|}
\hline Category & Requirement & Specific Details \\
\hline \multirow{3}{*}{ Asset Inventory } & Core Data & Equipment and Systems: HVAC, and Plumbing, Electrical, Mechanical and Fire Protection \\
\hline & \multirow{2}{*}{ Supporting Data } & Manufacturer/Vendor Data, Location Information (Service Zone), Description and Attributes \\
\hline & & Documents: O\&M Manuals, Warranties, Specifications, Instructions, Certifications, and Test Reports \\
\hline \multirow{7}{*}{$\begin{array}{l}\text { Maintenance } \\
\text { Management }\end{array}$} & \multirow{3}{*}{$\begin{array}{l}\text { Maintenance Data and } \\
\text { Field Data Collection }\end{array}$} & $\begin{array}{l}\text { Record maintenance activities, labor, materials, costs, quantities, location, condition and } \\
\text { accomplishments. }\end{array}$ \\
\hline & & Maintenance Data and Field Data Collection \\
\hline & & Maintenance Activity Data Collection \\
\hline & \multirow{4}{*}{ Managing work orders } & Open, modify and close work orders for maintenance activities \\
\hline & & Operationally schedule and reserve equipment, materials and personnel for any activities \\
\hline & & $\begin{array}{l}\text { Create flexible schedules (daily, weekly, bi-weekly, monthly) for maintenance activities based on } \\
\text { annual work plan and utilize prioritizing information as input }\end{array}$ \\
\hline & & $\begin{array}{l}\text { Update/revise work plan and schedule in response to changing needs and actual accomplishments and } \\
\text { track changes }\end{array}$ \\
\hline $\begin{array}{l}\text { Condition } \\
\text { Assessment }\end{array}$ & Asset Rating & Asset Age Rating, Asset Performance Rating, and Level of Maintenance Rating \\
\hline Space Management & Space Data & Space Type Description, Space Usage, and so on \\
\hline
\end{tabular}

If BIM had already been utilized in design and construction phase, with the owners' information requirements as a guide, it would provide a great opportunity for FM stuff to capture and transfer information effectively and efficiently. 
Thus, integrating the mentioned data in Table $\mathbf{1}$, some of these data should be captured in design and construction phase include:

- Data: Equipment/asset information, manufacturer/vendor information, location information, description, and attributes;

- Supporting information: specifications, warranties, operation and maintenance manuals, manufacturer instructions, certificates, and test reports etc.

\subsection{Format of Deliverables}

The owners not only struggle with the amount of data but also with the requirement of numerous data format that need to be provided when delivering the project. In the online survey, when asked about the methods used for managing the information handed over, among the respondents who do not use BIM the most used method is relying on printed or scanned documents with exception of the maintenance records and schedules in which the use of a CAFM or CMMS are the main method. Although the respondents who use BIM there those are also the main methods but in a more balanced fashion, with the exception of warranties and O\&M manual where printed or scanned documents is clearly the predominant method. There are a small percentage of respondents who are starting to use BIM for maintenance record, As-Built drawings and space management. This can be observed on Figs. (3 and 4).

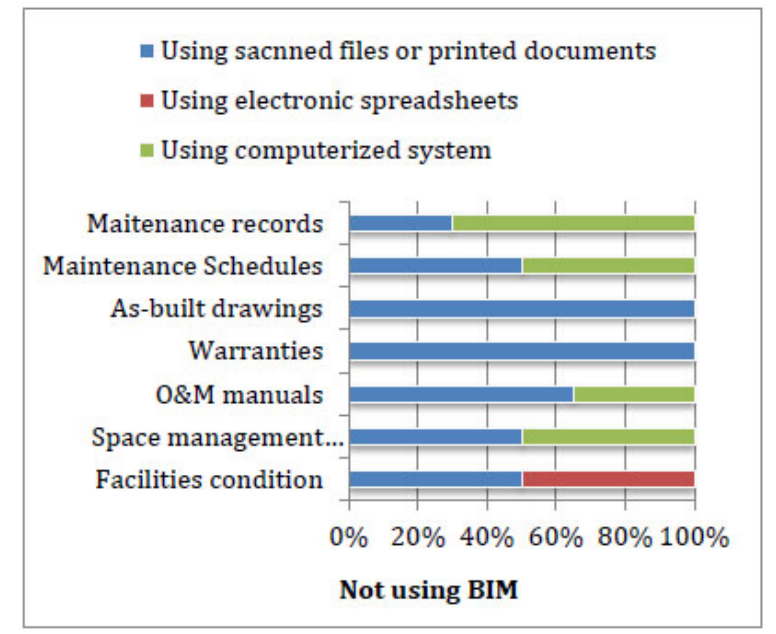

Fig. (3). Information management methods for different documentation at the O\&M stage for agencies who are not using BIM.

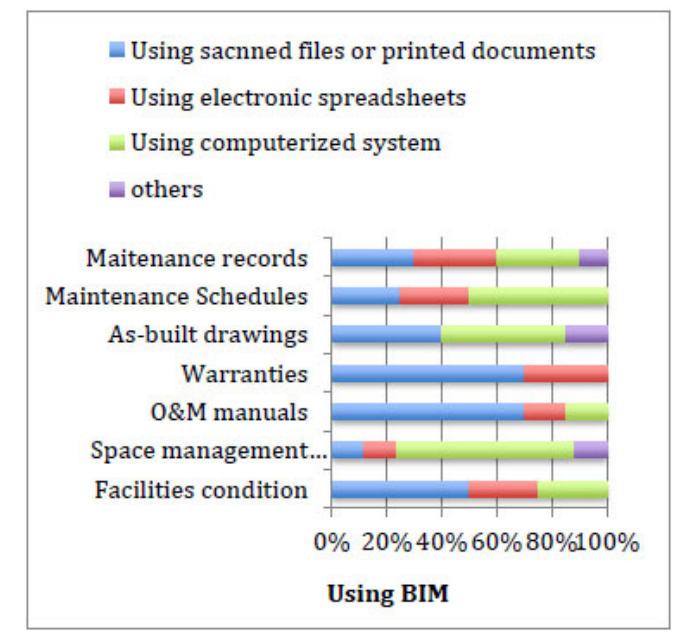

Fig. (4). Information management methods for different documentation at the O\&M stage for the agencies who are using BIM.

The interview findings demonstrated that current practice of information handed over for FM work is laborintensive and the handover deliverables mostly are 2D documents and drawings that are ineffective when being used in 
O\&M phase. The survey indicated that $65 \%$ of owners continue to request hard copies via digital media, and a set of scanned documents, excel files, or CAD files are used as part of the as-built deliverable. In addition, although there is the requirement for BIM use, the model is not currently employed for Operations and Maintenance (O\&M), reflecting that although BIM models carried part of the information needed for O\&M, manually input is still necessary. Only three respondents expressed that they would take an IFC or COBie files as part of the as-built handover package.

In most cases, these electronic files could be editable in the approved version of Microsoft Office suite, Autodesk AutoCAD Map 3D ${ }^{\mathrm{TM}}$, Civil 3D ${ }^{\mathrm{TM}}$, Navisworks ${ }^{\mathrm{TM}}$ and Revit ${ }^{\mathrm{TM}}$ et al. Some of them would be submitted to digital media or be uploaded to the owners' website directly or some other mutually agreeable means accepted by both contractors and owners. The Sound Transit agency is a case in point. The electronic 3D model should be submitted in Navisworks and delivered in NWD, NWC, and NWF formats. The native 3D files used to create the Navisworks model should be submitted in Autodesk Revit.

\subsection{Existing Difficulties in BIM Adoption for Facility Management}

It is admitted that BIM was first adopted by the designers, and then followed by the contractors. Currently, the industry has realized the importance of BIM for FM and began to develop the application tools to integrate BIM with the facilities management [25]. In spite of that, it is still very slow for the owners to adopt BIM in operation \& maintenance management and obtain the potential benefits, partly because most of the information needed by the owners for O\&M can be provided by non-graphical format. In addition, the FM industry does not have the knowledge, skillset, time, staff, or funding to conduct FM work by operating BIM Model, which is also an important reason for the difficulty of adopting BIM for FM.

Moreover, the handover process is never easy for the owners, especially in the information distribution process. It has been a big progress since the format of information transfers from hard copies to electronic copies, but the owner is still struggling with a huge amount of information that needs to be distributed to multiple project participants within the organization [20]. Although some owners have begun to use COBie and IFC standards to organize their information, there are still a lot of different information formats, e.g. CAD, Excel, Word, PDF, GIS etc. In general, the application of a new technology is always full of challenge, due to integration and interoperation problem concerning that the information formats you get are not what you really need.

Finally, the biggest challenge for BIM application in FM practices is to define these data requirements, and to identify by whom and when the data should be provided throughout the project life cycle. Moreover, due to BIM models always undergoes dramatic changes during project stages in terms of variety of versions, level of detail, model purpose, and responsibilities of different parties for integrating various discipline models, the owners face much more challenges when using BIM for FM.

\section{CONCLUSION AND FUTURE RESEARCH}

The primary goals of this paper are to assess the adoption and existing difficulties of BIM for FM in public transit agencies. An extensive literature review, online survey and an in-depth interview of a rail transit project are included to detail examine its current practices and requirements for the handover of information, operation and maintenance and asset management requirements as well as the future needs of the information system of the facilities management department generated by the use of BIM technology.

Besides, the findings summarized in this paper prove that BIM is valuable for the owners (transit agencies) and FM staff. It is important to establish a procedure for the use of the BIM during the O\&M stage as a central source of information for retrieving and populating CMMS, CAFM and/or EAM(Enterprise asset management) Systems as well as the use of the model for supporting maintenance and the space management procedures. Public Transit agencies are taking steps to improve their asset management, and to better integrate capital investment and maintenance work. With the information requirements from BIM for FM identified, data migration methods would be developed and executed to import data into CMMS, CAFM and/or EAM system for each business unit.

Moreover, to improve the implication of BIM for FM in the transit industry, the data and information requirements for the FM were identified in the paper. It would be beneficial for Transit agencies to encourage open dialog between design, construction and FM industries to resolve COBie issues, and work together to agree on classification and specification methods. Training Facility Managers in BIM specific skills to specify what data and information is needed from BIM to make facilities more efficient and effective is very necessary. 
In addition, the findings also implicate that utilizing BIM for FM in the public transit industry is still at the very beginning phase, and meanwhile a lot of difficulties and challenges need to be faced and fixed by the owners and other stakeholders together.

\section{CONFLICT OF INTEREST}

The authors confirm that this article content has no conflict of interest.

\section{ACKNOWLEDGEMENTS}

The authors would like to acknowledge the help of Prof. Dossick of University of Washington and Prof. Wang of China University of Mining and Technology in supporting the research program. The case study could not be worked out without the information provided by Seattle Sound Transit Agency.

\section{REFERENCES}

[1] M. Marzouk, and A.A. Aty, "Maintaining subways infrastructures using BIM", In: Proceedings of Construction Research Congress 2012, West Lafyatte, IN, USA, 2012, pp. 2320-2328. [http://dx.doi.org/10.1061/9780784412329.233]

[2] S. Lee, Y. Liu, S. Chunduri, R. Solnosky, J. Messner, R. Leicht, and C. Anumba, "Development of a process map to support integrated design for energy efficient buildings", In: ASCE TCCIT 2012 International Conference on Computing in Civil Engineering, Clearwater Beach, FL, 2012, pp. 261-268.

[3] M. Marzouk, M. Hisham, S. Ismail, M. Youssef, and O. Seif, "On the use of building information modeling in infrastructure bridges", In: Proceedings of $27^{\text {th }}$ International Conference-Applications of IT in the AEC Industry (CIB W78), Cairo, Egypt, 2010, pp. 01-10.

[4] N. Semaan, and T. Zayed, "A stochastic diagnostic model for subway stations", Tunnelling and Underground Space Technology, vol. 25, no. 1, pp. 32-41, 2010.

[http://dx.doi.org/10.1016/j.tust.2009.08.002]

[5] M. Marzouk, and A.A. Aty, "Maintaining Subways Infrastructures using BIM", In: Proceedings of Construction Research Congress 2012, West Lafyatte, IN, USA, 2012, pp. 2320-2328. [http://dx.doi.org/10.1061/9780784412329.233]

[6] A. Akcamete, B. Akinci, and J.H. Garrett, "Potential utilization of building information models for planning maintenance activities", In: Proceedings of the International Conference on Computing in Civil and Building Engineering, University Press: Nottingham, 2010, pp. 151-158.

[7] T. Eastman, and L. Sacks, BIM Handbook - A Guide to Building Information Modeling for Owners, Managers, Mdesigners, Engineers and Contractors., $2^{\text {nd }}$ ed. Wiley: Hoboken, 2011.

[8] V. Singh, N. Gu, and X. Wang, "A theoretical framework of a BIM-based multidisciplinary collaboration platform", Autommation Construction, vol. 20, no. 2, pp. 134-144, 2011. [http://dx.doi.org/10.1016/j.autcon.2010.09.011]

[9] Y. Arayici, "Towards building information modeling for existing structures", Structural Survey, vol. 26, no. 3, pp. 210-222, 2008. [http://dx.doi.org/10.1108/02630800810887108]

[10] C. Nicolle, and C. Cruz, "Semantic Building Information Model and multimedia for facility management", Web Information Systems and Technologies, Lecture Notes in Business Information Processing, vol. 75, pp. 14-29, 2011.

[11] B. Becerik-Gerber, F. Jazizadeh, N. Li, and G. Calis, "Application areas and data requirements for BIM-enabled facilities management", Journal of Construction Engineering Management, vol. 138, no. 3, pp. 431-442, 2011. [http://dx.doi.org/10.1061/(ASCE)CO.1943-7862.0000433]

[12] "General services administration (GSA) public buildings service office of the chief architect", In: GSA Building Information Modeling Guide Series 01-, GSA BIM Guide Overview, 2006.

[13] G. Mayo, and R. Issa, "Processes and standards for BIM closeout information deliverables for owners", In: International Conference on Computing in Civil and Building Engineering, pp. 673-680, 2014. [http://dx.doi.org/10.1061/9780784413616.084]

[14] E.W. East, "BIM for construction handover", Journal of Building Information Modeling, (National Institute of Building Sciences), pp. 28-35, 2007.

[15] "UniFormat", Available at: http://www.csinet.org/Home-Page-Category/Formats/UniFormat

[16] D. Haynes, A Tale of Two Exhibits - A Comparison of the CD301 and E3202 BIM Exhibits, PEPE and HAZAED LLP Construction Watch, 2009.

[17] P. Yee, C. Matta, C. Kam, S. Hagan, and O. Valdimarsson, The GSA BIM Story, Available at: http://www.fsr.is/LisaLib/ getfile.aspx itemid $=69952010$. 
[18] B. Brucker, M. Case, W. East, B. Hustone, S. Nachtighal, J. Shickley, S. Spangler, and J. Wilson, Building Information Modeling (BIM) A Roadmap for Implementation to Support MILCON Transformation and Civil Works Projects within the US Army Corps of Engineers, US Army Crops of Engineers: USA, 2006.

[19] "Department of Veterans Affairs", In: The VA BIM Guide, 2010. Available at: http://www.cfm.va.gov/til/bim/BIMguide/

[20] G. Mayo, B. Giel, and R. Issa, "BIM use and requirements among building owners", In: International Conference on Computing in Civil Engineering, 2012, pp. 349-356.

[http://dx.doi.org/10.1061/9780784412343.0044]

[21] "Indiana University", In: IU's BIM Requirements, 2009.

[22] "Computer Integrated Construction (CIC) Research Group", In: BIM Project Execution Planning Guide., Pennsylvania State University, 2010.

[23] "General Services Administration (GSA) Public Buildings Service Office of the Chief Architect", In: GSA Building Information Modeling Guide Series 08- GSA BIM Guide for Facilities Management., 2011.

[24] B. Hardin, BIM and Construction Management Proven Tools., Methods, and Workflows: Willey, Indiana, US, 2009.

[25] M. Tardif, Building Information Modeling: The Challenges and Opportunities for Building Owners, Owner's Perspective Summer, 2010, pp. $8-11$.

\section{(C) 2017 Liu and Gao}

This is an open access article distributed under the terms of the Creative Commons Attribution 4.0 International Public License (CC-BY 4.0), a copy of which is available at: https://creativecommons.org/licenses/by/4.0/legalcode. This license permits unrestricted use, distribution, and reproduction in any medium, provided the original author and source are credited. 